\title{
COMUNICAÇÃO INTEGRADA NO TERCEIRO SETOR: SEGMENTAÇÃO DE PÚBLICO-ALVO DO INSTITUTO PAZ NO TRÂNSITO NO FACEBOOK ${ }^{1}$
}

\author{
Hendryo Andrée
}

\begin{abstract}
Resumo
O objetivo deste trabalho é avaliar o trabalho de três semestres de uma consultoria desenvolvida por estudantes de Jornalismo das Faculdades Integradas do Brasil (UniBrasil) para o Instituto Paz no Trânsito (IPTRAN). Esta organização não-governamental foi formada em 2010, um ano após a morte de dois jovens em um acidente de carro em Curitiba, que envolveu um ex-deputado e teve enorme repercussão na mídia em todo o país. Este estudo faz um diagnóstico com o objetivo de criar um plano de comunicação institucional para IPTRAN e mostra como essas ações foram implantadas.

Palavras-chave: Assessoria de comunicação, assessoria de imprensa, plano de comunicação, comunicação integrada, terceiro setor.
\end{abstract}

\begin{abstract}
The aim of this paper is to evaluate the work of three semesters of an advisor consultancy developed by Journalism students from Faculdades Integradas do Brasil (UniBrasil) for the Instituto Paz no Trânsito (IPTRAN). This non-governmental organization was formed in 2010, one year after the death of two young men in a car accident in Curitiba, which involved a former deputy and had a huge media repercussion all over the country. This study makes a diagnosis in order to create an institutional communication plan for IPTRAN and shows how those actions were implanted.

Keywords: Social communication advisory, public relations, communication plan, integrated communication, third sector.
\end{abstract}

\section{Introdução}

Com as crescentes modificações pelas quais passa o campo do Jornalismo, tanto em função do desenvolvimento tecnológico - por vezes, de caráter meramente ufanista - quanto do amadurecimento das instituições democráticas no Brasil, o terceiro setor necessita cada vez mais olhar com zelo para ações de comunicação. Essa tendência ganha contornos mais nítidos à medida que algumas áreas do jornalismo tradicional definham, com a queda vertiginosa no número de empregos no mercado tradicional e da circulação de jornais impressos ${ }^{3}$ (BRASIL,

\footnotetext{
${ }^{1}$ Versão estendida do paper apresentado no $15^{\text {a }}$ Fórum Nacional dos Professores de Jornalismo, realizado em Curitiba no primeiro semestre de 2014.

2 Jornalista, professor do curso de Jornalismo das Faculdades Integradas do Brasil (UniBrasil). Mestre em Comunicação e Sociedade pela Universidade Federal do Paraná (UFPR) e doutorando em Jornalismo pela Universidade Federal de Santa Catarina (UFSC). E-mail: hendryoandre@gmail.com.

${ }^{3}$ A primeira edição de um estudo voltado à descoberta dos hábitos de consumo de mídia pela população brasileira apontou que $75 \%$ dos brasileiros não leem jornais impressos, enquanto que $6 \%$ exercem essa atividade diariamente (BRASIL, 2014, p. 64). A mesma pesquisa revela que a televisão continua sendo o veículo com maior abrangência na sociedade, já que $65 \%$ dos brasileiros a consomem todos os dias (Ibid., p. 20), mas aponta que os brasileiros com acesso à internet passam mais tempo à frente do computador do que da TV (BRASIL, 2014). Esses números apontam para uma reconfiguração no campo de produção.
} 
2014). No entanto, esses novos nichos de atuação ainda sofrem contestações dentro do campo jornalístico, a ponto de haver reflexos negativos na formação discente, principalmente quando se trata de um referencial teórico voltado a disciplinas ligadas à assessoria de imprensa ${ }^{4}$.

Kucinski (2005) é um dos principais exemplos de resistência, quando defende que o "vazio ético" que o jornalismo brasileiro vive se deve, entre outros fatores, aos novos significados que a profissão passou a ter, desde os anos 1980, após a regulamentação da assessoria de imprensa como atividade exercida por jornalistas. Muito embora a experiência brasileira seja única no mundo ao desvincular a assessoria de imprensa do campo de Relações Públicas (DUARTE, 2011), as três décadas em busca de legitimidade da área de assessoria de imprensa dentro do campo jornalístico não podem ser largadas aos quatro ventos. Dito de outra forma, é preciso admitir que o desafio maior seja o de aceitar e, consequentemente, adequar a atividade de assessoria de imprensa/comunicação aos parâmetros deontológicos do jornalismo, haja vista que essa área é que a mais absorve jornalistas (FENAJ, 2007).

Apenas essa tentativa de conciliação entre as ramificações profissionais seria capaz de tornar verdadeiramente anacrônica a disputa que segrega jornalistas de redação e assessores de imprensa. Para Chaparro (2011), o debate deve sobrepor esse dualismo que opõe os "bons" jornalistas (os de redação) aos “maus" jornalistas (os assessores de imprensa):

\begin{abstract}
Trata-se de um falso conflito. Porque não se deve cair na simplificação de ver no interesse público o valor que se opõe ao interesse particular. Essa seria a lógica moralista, como se de um lado estivesse o bem, do outro, o mal. O que se opõe a um interesse particular é outro interesse particular. E o jornalismo não tem como, nem por que, temer ou desprezar os interesses particulares; além de legítimos, está neles a engrenagem dos conflitos da atualidade, dos quais o jornalismo ocupa-se, com as ferramentas do relato voraz e do comentário independente (CHAPARRO, 2011, p. 20).
\end{abstract}

Assim, mais importante que a superada descaracterização da assessoria de imprensa como atividade jornalística é a necessidade de uma sólida formação humanística dentro da academia, visto que o fenômeno de absorção no mercado de trabalho por parte das assessorias de imprensa é hegemônico. O ponto central da discussão, portanto, passa a ser a necessidade de o campo jornalístico fomentar alguns parâmetros éticos para reger as ramificações da profissão.

Indo ao encontro desse princípio optou-se por trabalhar com o terceiro setor, área que oferece uma gama de alternativas para pensar criticamente a área de assessoria de

\footnotetext{
${ }^{4}$ No curso de Jornalismo da UniBrasil, a grade curricular reserva dois semestres letivos para essa atividade: Assessoria de Comunicação (40h), $6^{\circ}$ Período, com elementos e conceitos básicos que norteiam a atividade; e Laboratório de Assessoria de Imprensa $(80 \mathrm{~h}), 7^{\circ}$ Período, cuja finalidade é aprofundar e aplicar conceitos teóricos e práticos a respeito da atividade de assessoria de imprensa e desenvolver um projeto real na área (MARTINS et al, 2011).
} 
comunicação ${ }^{5}$. Assim, o trabalho de consultoria em comunicação junto a uma organização não governamental surgiu também em função da recorrente precariedade dos serviços de comunicação prestados ao terceiro setor, área comumente dependente de financiamentos para sobreviver (MARTINEZ, 2011), aliada à potencial repercussão do tema trânsito na atualidade. Como o terceiro setor é notoriamente marcado por orçamentos enxutos (ibid.), as atividades ligadas à comunicação tornam-se secundárias ou até mesmo inexistentes: no entanto, se as ações da área de comunicação "não são diretamente mensuráveis num balanço contábil [de uma instituição], podem significar [se aplicáveis], no mínimo, a simpatia da sociedade, a fidelidade dos consumidores, um bom relacionamento com trabalhadores, governos e sindicatos" (NASSAR; FIGUEIREDO, 2006).

Esses pressupostos nortearam o desenvolvimento do Plano de Ensino da disciplina Laboratório de Assessoria de Imprensa, ministrada em três semestres consecutivos junto a estudantes do $7^{\circ}$ Período do curso de Jornalismo das Faculdades Integradas do Brasil (UniBrasil). Com a incumbência de cumprir o elemento da ementa da disciplina que determina a aplicação de viabilidade numa instituição real (MARTINS et al, 2011), estendeu-se o convite ao Instituto Paz no Trânsito (IPTRAN).

Criado em meados de 2010, após uma colisão que vitimou dois jovens em Curitiba $^{6}$ e que se tornou um caso de grande repercussão midiática, a microempresária Christiane de Souza Yared fundou o IPTRAN, uma instituição sem fins lucrativos, não governamental e sem vínculos partidários. Hoje, o Instituto auxilia na reestruturação psicológica de familiares e vítimas não fatais de acidentes/crimes de trânsito (INSTITUTO PAZ NO TRÂNSITO, 2013). Embora tenha grande potencial de comunicação, o IPTRAN jamais havia tido até o início de 2013 qualquer trabalho de assessoria de comunicação.

Para tanto, a proposta lançada à gestão do IPTRAN foi de tentar aplicar um modelo de comunicação integrada, que "pressupõe uma junção da comunicação institucional, da

\footnotetext{
${ }^{5}$ A título de ilustração, há espaço dentro das Diretrizes Curriculares Nacionais para o Curso de Jornalismo (Portaria $n^{\circ}$ 203/2009) para o desenvolvimento de atividades supervisionadas em locais nos quais a área de comunicação encontra-se em nível embrionário, como é recorrente no terceiro setor. Ao considerar essa vertente, a atividade de estágio obrigatório, por exemplo, pode se transformar numa oportunidade para que a atividade possa ser realizada em instituições atualmente marginais para o campo da comunicação, como rádio, tevês, jornais e portais comunitários na internet, instituições do terceiro setor e movimentos sociais, assim como associações, igrejas e até mesmo para práticas empreendedoras.

${ }^{6}$ O episódio, ocorrido em 7 de maio de 2009, envolveu o então deputado estadual Luiz Fernando Ribas Carli Filho (acusado de estar alcoolizado), e deu início ao movimento "190 km/h é crime", que ganhou repercussão nacional, com a distribuição voluntária de 500 mil adesivos e o registro de 19 milhões de pesquisas em sites de busca (INSTITUTO PAZ NO TRÂNSITO, 2013). Christiane Yared, mãe de um dos jovens mortos na ocasião, começou a ser procurada por outras mães que viveram experiências semelhantes, na busca de consolo e orientação, fator que a incentivou a criar o IPTRAN.
} 
comunicação mercadológica e da comunicação interna, que formam o composto da comunicação organizacional" (CURVELLO, 2003, p. 97). Essa tentativa deveria atrelar as estratégias de gestão às de comunicação, ponto alto para que o IPTRAN possa se tornar, de acordo com o Plano de Comunicação Institucional (PCI) desenvolvido ao longo destes três semestres, numa referência em comunicação para o terceiro setor.

\section{A comunicação institucional em tempos de sustentabilidade}

Desde a consolidação da "cultura do automóvel”, prescrita pela aquisição e uso desenfreado do automóvel como símbolo mínimo de sucesso e ascensão social (LUDD, 2004), a violência no trânsito cresceu. Em janeiro de 2013, início da consultoria em comunicação junto ao IPTRAN, a frota de veículos em Curitiba havia ultrapassado a marca de 1,3 milhão de unidades (entre carros, motos, caminhões e ônibus). Os mais de 915 mil automóveis fazem com que a cidade tenha uma proporção maior de veículos por habitante que São Paulo. Os reflexos disso são variados e vão desde o crescimento de colisões graves e fatais (desde 2010, Curitiba ultrapassa a média de 300 mortes no trânsito por ano) até o aumento da poluição e congestionamentos, aspectos que somados influenciam diretamente na qualidade de vida da população.

Com base nesse cenário, a área de atuação do IPTRAN não poderia ficar restrita à cobrança de fiscalização, mas sim levar em consideração ações sustentáveis ${ }^{7}$, apropriadas para integrar o desenvolvimento econômico ao social e ao ambiental. Embora algumas dessas ações já acontecessem na prática em determinados projetos do IPTRAN (principalmente quanto ao viés do desenvolvimento econômico), outros pressupostos precisaram ser abordados durante o desenvolvimento do PCI: a promoção e o incentivo a ações para a melhoria de ciclovias e calçadas, a educação para novos e antigos motoristas, políticas de mobilidade urbana e os impactos ambientais dos meios de transporte, ações majoritariamente descobertas pela área de comunicação e que migram para a gestão do Instituto.

\footnotetext{
${ }^{7}$ A experiência profissional do autor em assessoria de comunicação na Universidade Federal do Paraná, ocasião na qual desenvolvia planos de comunicação em projetos de gestão ambiental em obras de infraestrutura e transportes, fortaleceu a perspectiva de instigar valores para tornar o IPTRAN num espaço democrático para discussões sobre temas como mobilidade urbana, trânsito sustentável e integração multimodal, desvinculando, em certo ponto, a imagem de que o IPTRAN foi criado por uma mãe em busca de justiça. Se essa imagem institucional se consolidasse, o Instituto perderia a essência de existência após o julgamento, principalmente em caso de condenação do ex-deputado. Para que essa perspectiva pudesse começar a ser posta em prática a sensibilidade de Christiane Yared e sua equipe de trabalho foi fundamental.
} 
Como a temática do trânsito é muito ampla e atinge integralmente a sociedade, a execução do PCI tem potencial para gerar parcerias com empresas públicas e privadas preocupadas com um trânsito sustentável, meios de comunicação, universidades, demais entidades do terceiro setor e cidadãos envolvidos com o tema - alguns exemplos já foram concretizados pela Comunicação Social, como a parceria junto à rede de Supermercados Condor para a arrecadação de equipamentos de segurança para bebês; o Grupo Artplan e a Escola Superior de Propaganda e Marketing (ESPM), ambos ligados ao desenvolvimento de campanhas que serão lançadas no primeiro semestre letivo de 2014. Além do auxílio nas divulgações de campanhas e projetos, o PCI também foi criado com o objetivo de vislumbrar fontes de recursos para a elaboração e execução de projetos futuros, atividade na qual ainda não é possível mensurar retorno.

\section{Contextualização e pressupostos básicos}

Desde a fundação, em 2010, a área de comunicação do IPTRAN nunca havia contado com um plano de comunicação integrada. Quando não realizados por profissionais de outras áreas do conhecimento - geralmente, da Pedagogia -, os trabalhos de comunicação ficaram restritos à prestação de assessoria de imprensa, encarregada por produzir releases de eventos e/ou ações pontuais e encaminhá-los junto aos meios de comunicação locais.

A elaboração do PCI foi realizada pelos estudantes durante os três semestres - como atividade ligada à disciplina - que puderam conhecer e aplicar os conceitos voltados à criação e (re)estruturação de uma assessoria de comunicação. A finalidade do trabalho no período foi a de estruturar as ações de comunicação do IPTRAN e vinculá-las ao planejamento estratégico da Instituição. Ao consolidar um modelo de gestão que integra a Assessoria de Comunicação Social ao gerenciamento dos projetos desenvolvidos pelo IPTRAN, o PCI visa a criar/fomentar uma cultura profissional no Instituto, capaz de torná-lo referência na gestão de comunicação integrada no terceiro setor.

Com o intuito de nortear o cumprimento dos valores e da missão institucional, o Plano visa auxiliar nas estratégias de Comunicação Social do IPTRAN, desde a alimentação do site institucional $^{8}$ (agenda da equipe assessorada, eventos e notícias) e o trabalho em redes sociais (sobretudo, Facebook ${ }^{9}$ e Twitter ${ }^{10}$ ), até a criação de uma estrutura de comunicação dentro do

\footnotetext{
${ }^{8} \mathrm{http} / / / \mathrm{www}$. iptran.org.br/

${ }^{9}$ https://www.facebook.com/InstitutoPazNoTransito

${ }^{10} \mathrm{https}: / /$ twitter.com/@InstPazTransito
} 
IPTRAN, integrando a comunicação a outros setores do Instituto. Dessa forma, a aplicação do PCI concretiza o pressuposto de que a informação deve ser uma ferramenta estratégica também para instituições do terceiro setor.

A partir da estruturação da comunicação e da constituição de um modelo de assessoria de comunicação, o IPTRAN passa por uma mudança de conceito, percebida como fundamental para uma instituição que defende os princípios democráticos. Com a estruturação da assessoria de comunicação, mais do que nunca a organização ganha potencial para difundir ideais nos quais acredita, disseminar perante a sociedade o trabalho desenvolvido e, de forma sistemática, fomentar/enriquecer o debate público para cumprir sua função social, cuja ênfase está sintetizada na missão institucional extraída do PCI: "Reduzir o número de vítimas de acidentes de trânsito por meio da promoção e do incentivo a práticas sustentáveis de mobilidade urbana".

Ao se integrar ao planejamento e à gestão estratégica do IPTRAN, o PCI tem potencial para alinhar missão e valores do Instituto, tanto com as ações de comunicação e educação quanto com a política de gerenciamento e utilização da comunicação para fortalecer a imagem institucional frente a seus stakeholders.

\section{Em busca de um público-alvo no facebook}

Com base no princípio de que o público-alvo é um grupo de pessoas que tem impacto nas decisões dos produtores e que a audiência dos produtos jornalísticos pode ser atingida com maior êxito a partir da identificação prévia do(s) público(s), optou-se por desenvolver uma pesquisa de opinião com usuários do Facebook (a ferramenta de comunicação mais viável para uma entidade cujo orçamento é estreito) que acompanham a Fan Page ${ }^{11}$ do Instituto direta ou indiretamente.

A pesquisa - que deve ser encarada como um esforço sistemático antes, durante e depois de uma atividade de comunicação (STACKS, 2008), o que implica necessariamente um estudo comparativo após o término do semestre letivo - é um importante instrumento para coletar fatos e opiniões pertinentes a respeito de um assunto, necessidade ou questão identificados. Durante o segundo semestre letivo de prestação de consultoria ao IPTRAN houve o desenvolvimento de uma pesquisa de opinião, cuja ênfase está mais voltada para o comportamento imediato do público (STACKS, 2008).

\footnotetext{
${ }^{11}$ A escolha por realizar a ação apenas no segundo semestre deveu-se ao baixo número de seguidores da página nos primeiros seis meses de 2013. No início do projeto, a Fan Page contava com apenas 87 seguidores. Até o fechamento deste artigo o número havia subido para 2.350. Na época da realização da pesquisa havia em torno de 1,3 mil usuários que seguiam a página.
} 
O levantamento, realizado mediante uma amostra probabilística, "obtida pelo sorteio de uma população na qual todos os possíveis respondentes ou objetos têm chance igual de ser selecionados para a observação ou medida" (STACKS, 2008, p. 13), teve como intenção não apenas criar um público-alvo, mas também descobrir quais parâmetros (aspectos de uma população de interesse) devem transmitir o conteúdo da mensagem para esse público-alvo. Nesse caso, a pesquisa deve tratar de descobrir quais elementos técnicos são centrais para que seja possível criar uma audiência fiel a seu programa (STACKS, 2008).

Com o objetivo de identificar comportamentos dos usuários no trânsito, principalmente no que se refere à relação entre álcool e direção (uma das principais frentes do IPTRAN), e, especificamente, de descobrir quais informações um público-alvo deve conhecer ou o grau de mudança no nível de conhecimento a partir da estratégia de comunicação (Ibid.), foram entrevistados 458 usuários do Facebook durante um mês. Segundo Arkin e Colton, para uma população acima de 100 mil pessoas (potencial de alcance almejado pelo IPTRAN), com 400 questionários é possível atingir uma margem de erro de 5\%. Dessa forma, a amostra da pesquisa atende a essa margem de erro (ARKIN; COLTON, 1970).

O questionário foi composto por 27 questões fechadas - e mais um campo de observações - e procurou num primeiro momento estabelecer um perfil socioeconômico dos usuários de Curitiba e Região Metropolitana (gênero, faixa etária, estado civil, escolaridade, renda e número de integrantes na família). Na segunda parte houve espaço para questões voltadas às relações do usuário com o trânsito (tempo de habilitação, tipo de carteira, se já havia sido punido com multa de trânsito). Por fim, foram abordados valores, estilo de vida e padrões de consumo desses usuários (tempo de convivência no trânsito, estilo de direção, significados do automóvel na vida social, consumo de bebidas alcoólicas) e elementos de educação no trânsito (bebida e direção).

\section{O perfil socioeconômico dos usuários do Facebook}

Entre os respondentes do levantamento houve predominância de homens (63\%) sobre as mulheres (37\%). A maior parte dos entrevistados tem entre 18 e 30 anos (57\%) e entre 31 e 40 anos (33\%). Em relação ao estado civil, a maioria dos entrevistados é formada por solteiros $(57 \%)$, pessoas mais propensas a frequentar bares e casas noturnas e, consequentemente, a consumir álcool, embora o percentual de casados também tenha relevância (40\%) - viúvos e divorciados somaram $3 \%$ das respostas. 
No que compete à escolarização, o perfil dos usuários que seguem direta ou indiretamente a Fan Page do IPTRAN é formado por pessoas que já concluíram o Ensino Superior (62\%). Já os usuários que possuem pós-graduação respondem a 17\%, percentual idêntico ao dos usuários com Ensino Superior incompleto. A taxa de entrevistados que não concluíram o Ensino Médio foi de 4\%. A Tabela 01 aponta a faixa salarial dos entrevistados:

TABELA 01 - RENDA DOS SEGUIDORES DIRETOS E INDIRETOS DA FAN PAGE

\begin{tabular}{lcc}
\hline FAIXA SALARIAL & TOTAL & PERCENTUAL \\
\hline Até R \$ 1.356 (até dois salários mínimos) & 08 & $2 \%$ \\
\hline $\mathrm{R} \$ 1.357$ a R \$ 2.712 (até quatro salários mínimos) & 54 & $12 \%$ \\
\hline $\mathrm{R} \$ 2.713$ a R \$ 4.746 (até sete salários mínimos) & 237 & $52 \%$ \\
\hline $\mathrm{R} \$ 4.747$ a R \$ 6.780 (até dez salários mínimos) & 49 & $11 \%$ \\
\hline $\mathrm{R} \$ 6.781$ a R \$ 10.170 (até quinze salários mínimos) & 85 & $19 \%$ \\
\hline Acima de R\$ 10.171 (acima de quinze salários mínimos) & 25 & $5 \%$ \\
\hline Fonte: Autor (2013). & &
\end{tabular}

Essas informações confirmam que as ações do IPTRAN nas mídias digitais atingem, por enquanto, majoritariamente pessoas mais novas, com alta taxa de escolarização e renda acima de quatro salários mínimos. Visto que a pesquisa foi aplicada em paralelo a atualizações de conteúdos voltadas à sustentabilidade e à mobilidade urbana (fator que ampliou, inclusive, o número de seguidores da página), a escolarização é um elemento propulsor para que os usuários optem por avaliar os problemas no trânsito não apenas pelo viés do caso que motivou a criação do Instituto. Tal característica acaba por ser reforçada quando são produzidos conteúdos voltados ao caso Carli Filho, oportunidade na qual se amplia o alcance das mensagens de forma exponencial entre não seguidores da página no Facebook.

Um exemplo merece atenção: em 20 de fevereiro de 2014, ocasião na qual houve o julgamento para decidir se o ex-deputado estadual Luiz Fernando Ribas Carli Filho (ver nota de rodapé 7) iria a júri-popular. Na oportunidade, a equipe postou uma imagem (Figura 01) da fundadora e presidente do IPTRAN, Christiane Yared, com os seguintes dizeres: "Hoje o Brasil inteiro aguarda por uma só sentença: Justiça! Júri popular ao ex-deputado Carli Filho. Assim esperamos". 


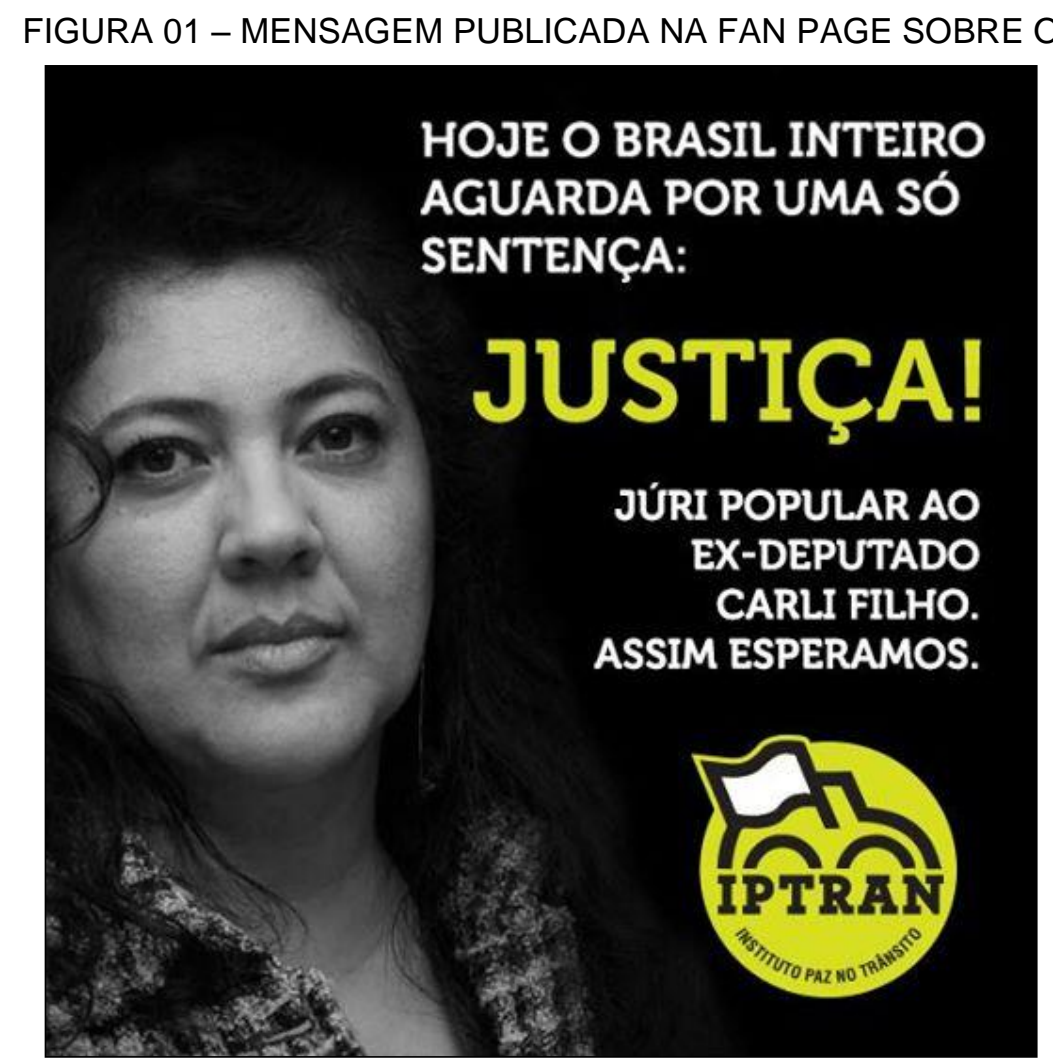

Fonte: IPTRAN (2014)

No total foram 5.592 compartilhamentos da imagem acima e, segundo as estatísticas fornecidas pelo gerenciador de páginas de Facebook, houve um total de 299.520 visualizações da imagem, números que quase atingem a marca de $10 \%$ da população de Curitiba e dos demais 28 municípios que formam a Região Metropolitana, estimada, segundo o IBGE, em 3,1 milhões de pessoas.

No entanto, após o julgamento não houve aumento considerável de alcance das publicações voltadas à mobilidade urbana e sustentabilidade, o que reforça o fato de que o Instituto precisa encontrar nichos de atuação para atrair outros grupos sociais, como as camadas populares, que possuem cada vez mais acesso ao automóvel como bem de consumo.

\section{A relação dos usuários do Facebook com o automóvel}

Entre os 458 entrevistados, 93\% possuem carteira de habilitação. Dentro deste universo, a maior parte $(88 \%)$ possui carteira do tipo B, aquela que contempla carros de passeio e outros veículos cujo peso não exceda 3,5 toneladas e cuja lotação não ultrapasse a oito lugares. Por outro lado, $10 \%$ possuem a carteira $\mathrm{AB}$, que contempla a autorização para conduzir os veículos 
descritos na categoria $\mathrm{B}$, mais veículos de duas ou três rodas, que contenham ou não um carro lateral (aspectos da Categoria A).

No que compete às infrações, $87 \%$ dos entrevistados que possuem habilitação já foram advertidos por algum tipo de multa de trânsito. O Gráfico 01 estabelece a quantidade e os tipos de multas recebidas pelos usuários:

\section{GRÁFICO 01 - QUANTIDADE E TIPOS DE INFRAÇÕES COMETIDAS}

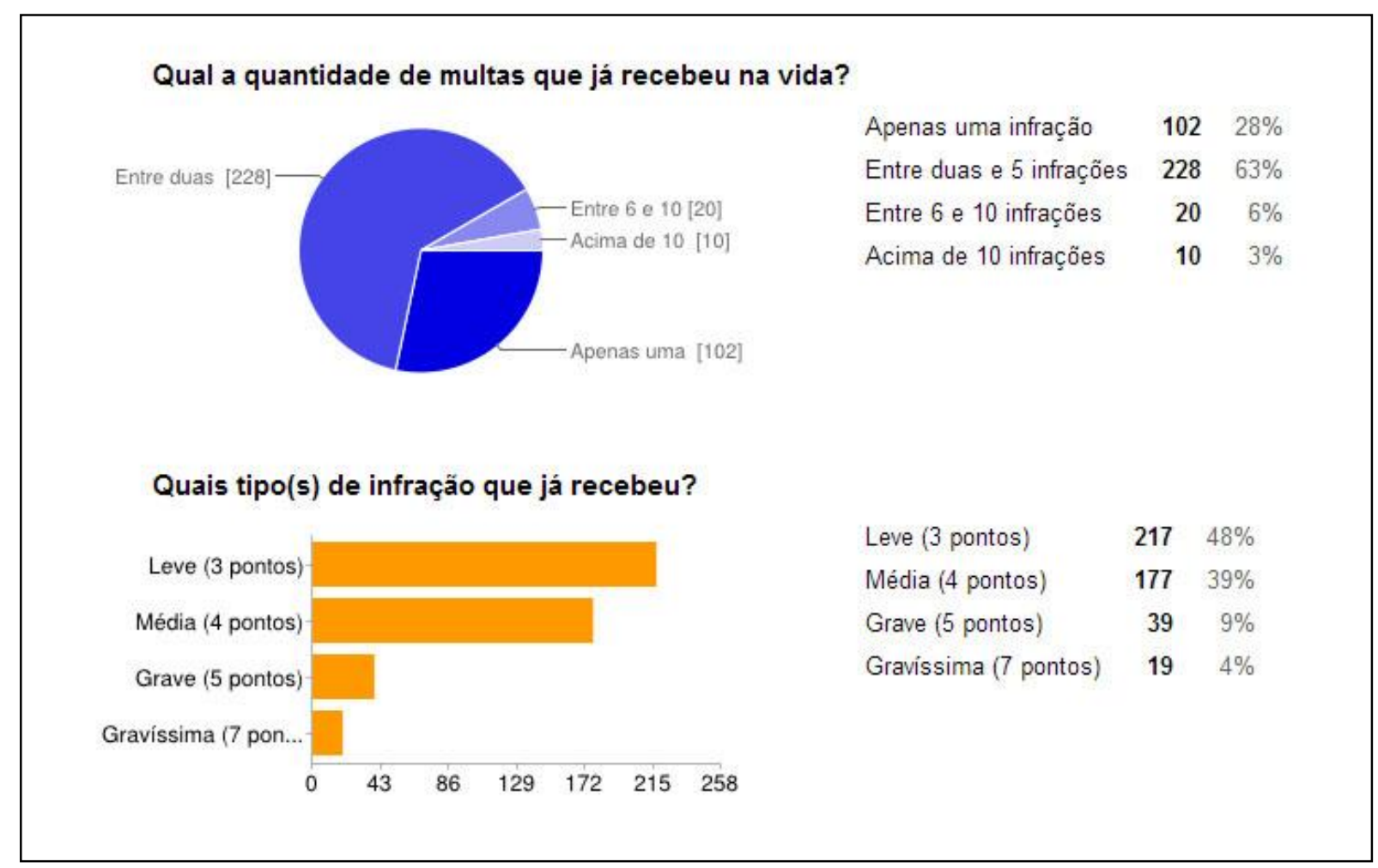

Fonte: IPTRAN (2014)

É possível observar que a fiscalização não é um elemento essencial para a redução da violência no trânsito, haja vista que $72 \%$ dos usuários declaram-se reincidentes no recebimento de autuações de trânsito. Ao mesmo tempo, é pertinente notar pelo perfil socioeconômico dos usuários que o acesso à educação formal não é garantia de conscientização no trânsito. Essa tendência se reforça mediante o questionamento sobre as mudanças que tornaram a Lei Seca mais rigorosa no início de 2013. Embora 68\% dos entrevistados afirmem conhecer as mudanças na legislação, $61 \%$ admitem que já dirigiram sob efeito de álcool após a atualização da lei. Quando questionados sobre o conhecimento acerca de campanhas educativas de trânsito que tenham foco o combate à combinação entre bebida e direção, $72 \%$ afirmaram que conhecem campanhas preventivas, mas na prática não as levam em consideração. 
O ponto-chave nas respostas se dá quando os usuários são questionados sobre qual perfil de motorista se enquadram. Apenas 6\% dos questionados admitem que são motoristas com um estilo agressivo, enquanto que $2 \%$ consideram-se desatenciosos. As autointitulações atencioso (com 58\% das respostas) e calmo (com 34\%) revelam a falta de consciência em torno da problemática do trânsito, principalmente porque há um relevante percentual de motoristas que afirmam dirigir embriagados e que se consideram "atenciosos" ou "calmos". Isso mostra que não há consciência de que as relações entre bebida e direção são conturbadas.

\section{Produtos segmentados}

Com base na idealização de um perfil de público, adotou-se no PCI uma preocupação em atingir tal público também nos outros produtos do projeto, como o site institucional e as redes sociais. Sobre o site institucional, a título de ilustração, a versão antiga, substituída pela atual no início de 2014, nunca havia tido qualquer tipo de atualização, nem das páginas fixas (Quem Somos, Projetos, Parceiros, IPTRAN Responde, entre outras), muito menos das áreas com vínculos mais factuais (Notícias e Eventos). Tal aspecto aponta para o fato de que a equipe do Instituto percebia a necessidade de possuir um site institucional, mas, em função da falta de recursos humanos e/ou financeiros e da ausência de cultura profissional voltada a práticas de comunicação, relegava o site a segundo plano.

No novo projeto foram priorizadas as seções mais factuais. Além disso, acrescentaramse espaços para agregar mais atores sociais ao Instituto, como a coluna Opinião, que reúne textos de especialistas envolvidos com a temática trânsito/mobilidade urbana e a TV IPTRAN, que trabalha com spots educativos replicados nas redes sociais. A TV IPTRAN, disponibilizada em canal no You Tube, apresenta vídeos com teor educativo sobre normas e soluções para a construção de um trânsito mais sustentável.

Outra mudança central destacada na página inicial é a valorização das fotos e do teor noticioso dos textos, além de espaço destacado para eventos promovidos pelo IPTRAN e/ou por seus parceiros institucionais.

No que compete à criação da página Sala de Imprensa, a pesquisa desenvolvida por Duarte e Carvalho (2011) inspirou a proposta. As organizações, segundo os autores, devem se adaptar e estabelecer novos níveis de interação, nos quais atualização, relevância, confiabilidade, facilidade de acesso e agilidade passam a ser conceitos-chave. Assim, o projeto da nova Sala de Imprensa herdou como características básicas os seguintes itens: agenda dos principais assessorados, mobilidade para a criação de áreas temáticas (para facilitar o acesso a 
informações de eventos ou outras ações particulares), articulação com os princípios e estratégias da organização, atualização e avaliação junto aos stakeholders, eficiente sistema de busca, coerência interna, comunicação direta com jornalistas e usuários interessados, inovação em conteúdo, dados para contato, galeria de fotos, galeria multimídia (com ênfase para a TV IPTRAN), releases, sistema de alerta e, por fim, visibilidade em destaque na página inicial (DUARTE; CARVALHO, 2011).

Assim, neste terceiro semestre letivo do projeto foi possível vislumbrar a utilização dos recursos fornecidos pelo site institucional - agregados ao Facebook - para atender as especificidades do público-alvo das redes sociais, integrando ambas as ferramentas.

\section{Considerações finais}

Ainda que o projeto esteja em fase de execução e não haja mensuração dos resultados, é possível perceber algo inovador no que compete à forma de atuação dos estudantes: já com uma formação delineada no sétimo período, ao contrário de outras disciplinas específicas do curso, os alunos e alunas podem trabalhar diretamente com as mídias que mais se adaptam ou que, porventura, tenham interesse em conhecer - algo que exemplifica o interesse e crescimento das atividades junto a rede social Facebook. A aplicação de um projeto laboratório em consultoria de comunicação, com uma proposta e cliente reais, também complementam a reflexão teórica acerca da atividade jornalística, trazendo para o campo da reflexão os novos papéis da comunicação institucional.

Ao tentar conciliar ensino e pesquisa, os produtos oriundos da atividade acadêmica reproduzem elementos direcionados à audiência que segue a Fan Page. Potencialmente, os resultados da pesquisa têm capacidade para elencar e prever novas ações para ampliar a área de atuação do Instituto.

Embora o pilar da conscientização seja importante e contínuo mesmo para um públicoalvo que majoritariamente tem acesso à educação formal, a intenção é desenvolver, em parceria com a Escola Superior de Comunicação e Marketing (ESPM) algumas campanhas de teor mais apelativo, que estabeleçam causas e consequências entre bebida e direção e entre o uso de telefones celulares durante o processo de condução.

Uma dessas campanhas já foi desenvolvida. Aproveitando uma nova moda de selfies que atingiu a internet no início de 2014, com selfies com fita adesiva no rosto (extraída de uma cena protagonizada pelo ato Jim Carrey, no filme "Sim Senhor"), profissionais da ESPM e da Agência Artplan idealizaram uma peça publicitária para fazer uma alusão entre álcool e direção. 
A campanha "Quando é pra sempre não tem a menor graça" conquistou o terceiro lugar no Festival de Criatividade de Cannes de 2014. A título de ilustração, a Figura 02 traz uma das imagens montadas para a campanha.

\section{FIGURA 02 - CAMPANHA "QUANDO É PRA SEMPRE NÃO TEM A MENOR GRAÇA"}

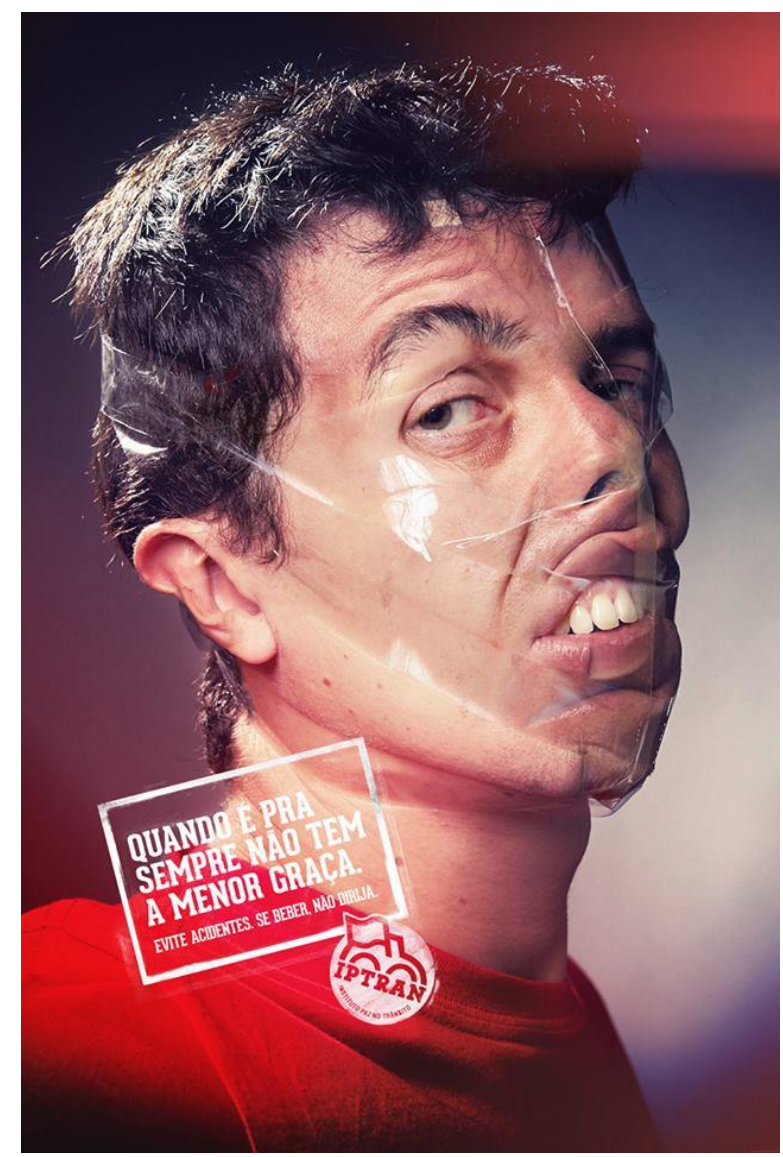

Fonte: IPTRAN (2014)

Além dessa campanha, o trabalho com postagens relacionadas à educação no trânsito foi constantemente realizado após a identificação do público-alvo.

(Artigo recebido em 01/05/2014, aprovado em 03/06/2014)

\section{REFERÊNCIAS}

ARKIN, Herbert; COLTON, Raymond R. Statistical methods. Ed.5. New York: Barnes \& Noble, 1970.

BRASIL. Pesquisa Brasileira de Mídia 2014: Hábitos de consumo de mídia pela população brasileira. Brasília: Secom, 2014. 151 p. Disponível em: 
<http://www.fndc.org.br/publicacoes/pesquisas-e-relatorios/pesquisa-brasileira-de-midia2014-habitos-de-consumo-de-midia-pela-populacao-brasileira/>. Acesso em: 18 mar. 2014.

CHAPARRO, Manuel Carlos. Cem anos de assessoria de imprensa. In: DUARTE, Jorge (org.). Assessoria de imprensa e relacionamento com a mídia: teoria e técnica. 4. ed. São Paulo: Atlas, 2011.

DUARTE, Jorge; CARVALHO, Nino. Sala de imprensa online. In: DUARTE, Jorge (org.). Assessoria de imprensa e relacionamento com a mídia: teoria e técnica. 4. ed. São Paulo: Atlas, 2011.

DUARTE, Jorge. Assessoria de imprensa no Brasil. In: DUARTE, Jorge (org.). Assessoria de imprensa e relacionamento com a mídia: teoria e técnica. 4. ed. São Paulo: Atlas, 2011.

FEDERAÇÃO NACIONAL DOS JORNALISTAS. Manual de Assessoria de Comunicação: Imprensa. Brasília: Fenaj, 2007. 45 p. Disponível em: <http://www.fenaj.org.br/mobicom/manual_de_assessoria_de_imprensa.pdf $>$. Acesso em: 18 mar. 2014.

INSTITUTO PAZ NO TRÂNSITO (Curitiba). Instituto Paz no Trânsito. Disponível em: <http://www.iptran.org.br/>. Acesso em: 01 jun. 2013.

KUCINSKI, Bernardo. Jornalismo na era virtual: ensaios sobre o colapso da razão ética. São Paulo: Perseu Abramo, 2005.

LUDD, Ned. Carros e remédios. In: LUDD, Ned (org.). Apocalipse motorizado: a tirania do automóvel em um planeta poluído. São Paulo: Conrad Editora do Brasil, 2004.

MARTINEZ, Maria Regina Estevez. Implantando uma assessoria de imprensa. In: DUARTE, Jorge (org.). Assessoria de imprensa e relacionamento com a mídia: teoria e técnica. 4. ed. São Paulo: Atlas, 2011.

MARTINS, Maura et al. Projeto Pedagógico do Curso de Jornalismo. Curitiba: Escola de Comunicação, 2011.

NASSAR, Paulo; FIGUEIREDO, Rubens. O que é comunicação empresarial. São Paulo: Brasiliense, 2006.

STACKS, Don W. Dicionário de Mensuração e Pesquisa em Relações Públicas e Comunicação Organizacional. São Paulo: ABERJE, 2008. 